\title{
Probabilistic evaluation of the railway track infrastructure components failure risk
}

\author{
Anatoliy Shtompel, Liudmyla Trykoz ${ }^{*}$, Dmytro Borodin, Andrii Ismagilov, and Yaroslav \\ Chmuzh \\ Ukrainian State University of Railway Transport, Feierbakh Square 7, 61050, Kharkiv, Ukraine
}

\begin{abstract}
The permanent way components are of key importance for safe operation of a rail way. The country regulations, in particular in Ukraine, specify the operational life limits for the permanent way but they do not define any tool or method to predict deterioration of the permanent way condition over time. The study is aimed to develop a method for assessing failure risk of the permanent way components in operation. There was a method offered to evaluate risk of failure of the permanent way components of the welded tracks, which considers accumulated freight load on a rail section. Each element of the permanent way, such as rails, fasteners, sleepers, ballast layer, accumulates defects and deformations. The accumulation rate is different for the above components and depends on freight traffic. There was probability of failure-free operation calculated for each component for the first time and an integral fatigue index of the construction has been offered which considers freight traffic accumulated load. There was a mathematical failure forecast model developed which allows planning of track maintenance. The model allows to take into account operating conditions of a railway section. The results of simulation are presented in various diagrams.
\end{abstract}

\section{Introduction}

Risk is not avoidable in railway operation. It is defined as a measure combination of hazard likelihood and severity of consequences of an operational failure. Transport safety implies several aspects: railway infrastructure safety, transport system operation safety, goods safety, health and life safety of the passengers and employees. The term "safety" does not mean complete absence of any hazard in railways operation. It means an ability to ensure safe cargo and passenger traffic in case of an emergency of failure. The reliability theory defines emergency prevention as ability to ensure long-term fail-free operation of each component of the railway infrastructure. It is not enough to use those tools for acquisition and processing of data related to failure rates of the infrastructure components. There is a more important task in railway transport operation, which is risk management involving timely detection of negative trends in each infrastructure component, prediction of possible consequences and decision making on how to prevent or minimize negative impact.

* Corresponding author: 1vtrikoz@,ukr.net 
Such a probabilistic simulation can be used in the railways engineering and construction $[1,2]$. As it is shown in [1], there are numerous risk factors in railway construction, such as decision making, engineering, construction, technology, quality, investment, natural disasters, force majeure circumstances, etc. It has been is proven that risk management is a practical method in the railway construction and an important tool for design risk minimization, construction quality improvement and efficient project cost management. A quantitative risk analysis can be performed for various railway infrastructure components such as tunnels [3], bridges [4, 5], rolling stock [6]. Some authors introduce the concept of "critical element" to evaluate the failure risk [7-9]. The above papers present the results of risk assessment models development based on railway accident scenarios. The researchers also have tried to create an efficient method that allows to evaluate significance of railway infrastructure elements. The road junctions, bus and train stations, bridges and tunnels were defined as the potentially significant elements of the infrastructure. This approach is based on events that have already happened (accidents). In our opinion, it does not allow to predict the risks of daily "aging" of the whole railway and, accordingly, to plan preventive repair of the track to avoid accidents.

Some researchers propose to create an information system for railway risk management. They consider using of a large amount of daily data: results of dynamic and static monitoring of railway lines and bridges, overhaul and medium repairs data, maintenance data and records about bridges and tunnels failures [10]. Such systems should be able to acquire, store and manage huge amounts of data related to condition of railway, bridges and tunnels. The data management and processing should be combined with daily operations and monitoring to obtain information about the status of the permanent way. Based on big data collected over long period of time, the authors tried to define how condition of track changes with time and to develop a model to predict it. They want to change a concept of track maintenance. The new approach should be based on preventive and condition based maintenance which makes it absolutely different from the existing approach based on scheduled maintenance or repair-after-failure concept. If this new approach will be implemented than the managers in all levels will be provided with tools to monitor railway equipment in real time and increases efficiency of management.

The study [11] was aimed to improve railroad drift simulation based on comprehensive field research. The authors apply both engineering and statistical data processing approach. They have collected and processed comprehensive data about track condition related to approximately $100 \mathrm{~km}$ of a railway line. The data acquisition was performed during two years. They have studied the factors influencing track deterioration, including load traffic, inspection monitoring, track quality. This allowed them to find correlations between the influencing factors and road deterioration. The forecasting approach offered in [12] offers a method to evaluate track segment drift. The evaluation results could be used to make decisions on allocation of limited budget. Probabilistic safety assessment becomes quite complicated in complex systems with several failure modes. Such systems can be simulated by Marcov processes which suppose multiple states and transitions [13]. There is a probabilistic estimate approach to risk assessment for infrastructure networks with high risk of flood presented in [14]. The proposed method of risk analysis combines both probability of the infrastructure failure and expected efficiency of the network infrastructure or loss of capacity due to component failure.

All the above mentioned studies do not consider risk of failure of the components of the permanent way structure. However, the permanent way condition determines availability of any infrastructure component. The purpose of this study is to establish a method of evaluation of failure risk of the permanent way with welded railway tracks subjected to load traffic. 
The track permanent way experiences load from rolling stock. The level of this load significantly affects operation of the track and causes the changes in its technical condition. The more load traffic passes the section the higher is tendency of deterioration of permanent way technical condition due to the accumulation of residual deformations in it and failure of the components. All this leads to decrease of operational reliability of the permanent way structures and the deterioration of the train traffic safety. Maintenance is struggling to slow down this process of "aging" of the track. The regular maintenance includes, in particular, works to eliminate failures of permanent way components which happened in operation. In order to be able to plan maintenance and repair of a railway, it is necessary to have appropriate mathematical forecasting models of permanent way components failure. Those should take into account operational conditions of the railway section. The models require an appropriate method of permanent way failure probability evaluation.

\section{Development of the mathematical model of the probability of failure-free operation of the track permanent way}

In order to remove negative effects of deterioration of operating conditions at a certain site, an appropriate system to manage railway availability is required. This system should be based on technical condition status of the way section derived from information about failure of the track permanent way (TPW) components. The applicable regulations define the operational limits (performance criteria) of the TPW construction at certain stages of its life. The assembled rails and sleepers are considered as basis (welded heat-treated rails, prestressed concrete sleepers with a sleeper density $N_{s l}=1840 \mathrm{pcs}$ per km, an intermediate bonded-bolted fastening, crushed stone ballast). This type of rails operates in almost $75 \%$ of the main railways of Ukraine.

It is accepted that the process of accumulation of single defects of rails as a function of traffic load is the one defining change of railway track condition in a particular section. If replacement of a defect rail is assumed to be a failure, then the failure probability of $F_{R}(T)$ and faultless operation of rails $P_{R}(T)$ by the moment of traffic load accumulation $T$ is

$$
\begin{aligned}
& F_{R}(T)=r_{R}(T) / N_{R} ; \\
& P_{R}(T)=1-r(T) / N_{R},
\end{aligned}
$$

where $r_{R}(T)$ is the number of rail failures by the moment of traffic load accumulation $T$; $N_{R}$ is the number of rails per $1 \mathrm{~km}$ of track. For $N_{R}=80 \mathrm{pcs} / \mathrm{km}$ and $r_{R}(T)=10 \mathrm{pcs} / \mathrm{km}$ (for R65 rail type), $F_{R}(T)=0.125$, and $P_{R}(T)=0.875$.

Practical experience shows that one of hundred defective rails can not be detected by existing flaw detectors and it gets damaged by the train running over. Let assume the probability of breaking a defective rail $F_{R}=0.01$, then the probability of failure after replacing 10 rails (per $1 \mathrm{~km}$ of track) is $F_{R}=0.125 \cdot 0.01=0.00125$, and the probability of fail-safe operation is $P_{R}=0.99875$. It is known that not every break of a defective rail under train causes its get off from track or accident. Therefore, the actual reliability of the rails (under the condition that the defective rails are replaced in scope of 10 pcs per km during regular maintenance of the TPW) can be estimated as $P_{R}=0.999$, which allows to classify the rails as highly reliable components according to the valid classification.

A track is assumed to be defective if there are 100 defective concrete sleepers found per $1 \mathrm{~km}$ of track. Taking the sleepers density $N_{s l}=1840$ sleepers per $\mathrm{km}$, the failure probability of this component is $F_{s l}(T)=100 / 1840=0.054$, and probability of its failurefree operation is $P_{s l}(T)=0.946$. These values $F_{s l}$ and $P_{s l}$ are set for a case when the defective sleepers are not replaced in the section. This is a hypothetical case and it is not 
realistic. If $F_{s l}=F_{R}=0.01$, then the permissible number of defective concrete sleepers can be determined per $1 \mathrm{~km}$ of track $r_{s l}=N_{s l} F_{s l}(T)=1840 \cdot 0.01 \approx 20$ sleepers. In this case, probability of failure-free operation of the specified component is $P_{s l}=0.99$.

The limit amount of defective rails fastenings allowed per $1 \mathrm{~km}$ (for the life cycle of the TPW) is set by regulations at $25 \%$ of the total number of sleepers (the total amount of defective rail pad plates and fixing bolts is considered). Then, probability of failure in the operation of the fastenings is equal to $F_{f a s}(T)=0.25$, and the probability of its failure-free operation is $P_{\text {fas }}(T)=0.75$. As in the previous case (concrete sleepers), the obtained values of $F_{f a s}$ and $P_{f a s}$ are calculated for the unrealistic hypothetical situation, when the defective rail pad plates and fixing bolts are not replaced regularly in a site. Taking $F_{\text {fas }}=F_{R}=0.01$, it is possible to set the permissible number of defective fastening components per $1 \mathrm{~km}$ of the track in operation: $r_{f a s}=N_{f a s} \cdot F_{f a s}(T)=1 \%$ (from the total number of rail pad plates and fixing bolts). The probability of failure-free operation of fastening is $P_{\text {fas }}=0.99$. Indicators $r_{R}, r_{s l}$ and $r_{f a s}$ should be considered as criteria for making decision about rehabilitation of the TPW in a certain section. They provide quantitative evaluation of technical condition of the rail and sleeper grid (RSG).

Considering the known values of the probability of failure-free operation of the $i$-th element (for a specific section of the track), the integral indicators for the TPW are defined for accumulated traffic load

$$
\begin{aligned}
& P_{R S G}=P_{R} \cdot P_{s l} \cdot P_{f a s} ; \\
& F_{R S G}=1-P_{R S G} .
\end{aligned}
$$

One can calculate for the above considered cases as follows:

- in case no maintenance done in the track of a railway section

$P_{R S G}=0.875 \cdot 0.946 \cdot 0.75=0.62 ; F_{R S G}=1-0.62=0.38$;

- in case the defective TPW components are regularly replaced in the section

$P_{R S G}=0.999 \cdot 0.99 \cdot 0.99=0.98 ; F_{R S G}=1-0.98=0.02$.

The value $P_{R S G}$ is used to rank track sections (in a certain area) by their reliability and traffic load accumulated. This ranking is a part of the system of railroad maintenance planning.

During track operation, polluted ballast is mixed with water and pressed out from under the sleepers when the train rolls over. This phenomenon is named "track pumping". There is the relationship between the number of track pumpings $m_{\text {pum }}$ (sleepers per $\mathrm{km}$ of track) and the volume of the load traffic $T$ (million tons gross) passed over the welded rails section (welded R65 type rails, prestressed concrete sleepers, gravel ballast) with averaged operating conditions [15]

$$
m_{\text {pum }}=1.6 \cdot 10^{-6} T^{3} .
$$

A single track pumping (per $1 \mathrm{~km}$ of track) is not considered as a failure of the ballast layer. This defect is usually fixed during regular maintenance of the track structure at the site. The regulations specify the number of ballast pumpings per $1 \mathrm{~km}$ of track as the main criterion planning maintenance in the section. The maximum permissible number of sleepers with local pumpings is $3-15 \%$ of the number of sleepers per $1 \mathrm{~km}$ and the absolute value depends on sleepers density. Obviously, this number of pumping per $1 \mathrm{~km}$ of track can be considered as a failure of the ballast layer. The probability (risk) of occurrence of pumpings of crushed stone ballast during the accumulation load traffic is based on the formula

$$
F_{\text {pum }}\left(t_{i}\right)=m_{\text {pum }}\left(t_{i}\right) / N_{s l},
$$

where $m_{\text {pum }}\left(t_{i}\right)$ is the number of pumpings at time $t_{i} ; N_{s l}$ is the sleeper density. 
Taking into account the formula (5) for the continuous welded rails (with $N_{s l}=1840$ sleepers per $\mathrm{km}$ ), the mathematical model for estimation of the failure probability $F_{\text {pum }}\left(t_{i}\right)=f\left(T_{i}\right)$ will be as follows

$$
F_{\text {pum }}\left(t_{i}\right)=8,7 \cdot 10^{-10} T^{3}
$$

The intensity of occurrence of ballast pumpings within the track segment is determined by the formula

$$
\lambda_{\text {pum }}\left(t_{i}\right)=m_{\text {pum }}\left(t_{i}\right) / N\left(t_{i}\right) \Delta T,
$$

where $N\left(t_{i}\right)$ is the number of sleepers without ballast pumpings at time moment $t_{i} ; \Delta T$ is the value the passed gross load at the considered time interval. In this case, the function $\lambda_{\text {pum }}\left(t_{i}\right)=f\left(T_{i}\right)$ is presented as follows:

$$
\lambda_{\text {pum }}\left(t_{i}\right)=4.3 \cdot 10^{-10} T^{2.14} .
$$

This model is received by processing the pairs of values $\lambda_{\text {pum }}$ and $T$ in load traffic accumulated interval $T=50 \div 700$ million tons gross. The verification of formula (9) by Fisher's criterion has confirmed that the offered model is correct. Thus, the number of pumpings of crushed stone ballast for $1 \mathrm{~km}$ of welded rail corresponding to $3 \%$ (from $N_{s l}$ ) and $15 \%$ (from $N_{s l}$ ) should be expected at 330 and 560 million tons of accumulated load traffic gross respectively. This corresponds to the probability of occurrence 0.03 and 0.15 , respectively.

The probability of failure-free operation $P_{T P W}\left(t_{i}\right)$ is used to evaluate reliability of the TPW. It is calculated at a specific moment of time $t_{i}$ (after the accumulation of a specific load traffic $T_{i}$, in million tons gross) according to the formula

$$
P_{T P W}\left(t_{i}\right)=P_{R}\left(t_{i}\right) \cdot P_{s l}\left(t_{i}\right) \cdot P_{\text {fas }}\left(t_{i}\right) \cdot P_{\text {pum }}\left(t_{i}\right),
$$

where $P_{R}\left(t_{i}\right) ; P_{s l}\left(t_{i}\right) ; P_{f a s}\left(t_{i}\right) ; P_{\text {pum }}\left(t_{i}\right)$ are the probability of failure-free operation (at the time $\left.t_{i}\right)$, respectively, of rails, sleepers, intermediate fastenings and ballast layer.

The welded rails are split into segments of $12.5 \mathrm{~m}$ for the purpose of evaluation of their reliability (this is length of the rail insert that is welded into the rail string when its integrity is finally restored). Rails of equalizing segments are excluded. The total number of single defects $m_{R}$ (pcs per km) of thermally reinforced rails of the R65 type (within the rail string) as a function of accumulated load traffic $T$, million tons gross (for areas with an average axle load of $155 \mathrm{kN}$ and a train speed of $100 \mathrm{~km} / \mathrm{h}$ ) can be defined as follows

$$
m_{R}=0.56 \cdot 10^{-8} T^{3}
$$

The probability of rail failures in operation is defined as follows

$$
F_{R}\left(t_{i}\right)=m_{R}\left(t_{i}\right) / N_{R}
$$

where $N_{R}$ is the number of $12.5 \mathrm{~m}$ long rail sections per $1 \mathrm{~km}$ of track.

In this case, this value is calculated as

$$
F_{R}\left(t_{i}\right)=0.35 \cdot 10^{-10} T^{3} .
$$

Based on the materials [15], the probability of sleeper failure (for the considered construction of the TPW) can be described by the mathematical model

$$
F_{s l}\left(t_{i}\right)=7.93 \cdot 10^{-10} T^{2}
$$


It is considered that a system consisting of connected components (the node of fastening) is operational in the case all its components are operational (not failed). The corresponding data processing allowed to define the following mathematical models for evaluation:

- the probability of fastening failures (for the construction of the TPW with $N_{s l}=1840 \mathrm{pc} / \mathrm{km}$ ) as a function of accumulated traffic load

$$
F_{\text {fas }}\left(t_{i}\right)=28.3 \cdot 10^{-10} T^{3},
$$

- total fastening failure units due to defects during operation

$$
m_{\text {fas }}=10.4 \cdot 10^{-6} T^{3} .
$$

The verification of formulas (15) and (16) in accordance with Fisher criteria confirmed the proposed models are correct.

The rate of fastening failure in a track section is defined by the formula

$$
\lambda_{\text {fas }}\left(t_{i}\right)=m_{\text {fas }}\left(t_{i}\right) / N\left(t_{i}\right) \Delta T,
$$

where $N\left(t_{i}\right)$ is the number of fastenings without failure at the time $t_{i}$.

In this case, the function $\lambda_{\text {fas }}\left(t_{i}\right)=f\left(T_{i}\right)$ is described by following mathematical model

$$
\lambda_{\text {fas }}\left(t_{i}\right)=3.5 \cdot 10^{-10} T^{2.4} \text {. }
$$

This model is received by processing pairs of values $\lambda_{\text {fas }}$ and $T$ in the interval $T=100 \div 600$ million tons gross. It is verified by Fisher criteria. A failure of fixing assembly does not mean a failure of the system of rail links to supports. According to the valid regulations, the transversal stability of the rail line is considered to be partially failed when 3 or more neighboring linking assemblies fail. The researches defined the value of probability of failure-free operation of a system of transverse links of the rails with supports through intermediate fastenings. The data processing allowed to define how failure probability of the system changes (the probability of the occurrence of the critical sets of failed assemblies) $F_{\text {fas }}{ }^{\text {bush }}\left(t_{i}\right)$ as a function of traffic load accumulated

$$
F_{\text {fas }}^{\text {bush }}\left(t_{i}\right)=5.5 \cdot 10^{-20} T^{7} \text {. }
$$

Based on the calculations made the following mathematical model has been received for the function $P_{T P W}\left(t_{i}\right)=f\left(F_{R}\left(t_{i}\right), F_{s l}\left(t_{i}\right), F_{\text {fas }}\left(t_{i}\right), F_{\text {pum }}\left(t_{i}\right)\right)$

$$
P_{T P W}\left(t_{i}\right)=-2.7 \cdot 10^{-6} T^{2}+0.5 \cdot 10^{-3} T+0.99 .
$$

The formula has been verified in accordance with Fisher criteria. The correlation factor and determination factor are calculated respectively as $r=0.9996$ and $r^{2}=0.9992$. The formula (20) can be applied within the range from 200 million tons gross to 700 million tons gross. Calculation results by using formula (20) is given in the table 1.

Table 1. The probability of failure-free operation of the TPW as function of accumulated traffic load

\begin{tabular}{|c|c|c|c|c|c|c|c|}
\hline $\begin{array}{c}\text { Accumulated traffic } \\
\text { load, } \\
\text { million tons gross }\end{array}$ & 0 & 200 & 300 & 400 & 500 & 600 & 700 \\
\hline $\begin{array}{c}\text { Probability of failure- } \\
\text { free operation of the } \\
\text { TPW }\end{array}$ & 0.990 & 0.982 & 0.897 & 0.758 & 0.565 & 0.318 & 0.017 \\
\hline
\end{tabular}




\section{Application of the mathematical model of the to the section of the railway of Ukraine}

The formula (20) is used for a hypothetical case, which assumes that the failed components of TPW are not fixed regularly during maintenance. This explains the sharp falling of the function $P_{T P W}\left(t_{i}\right)=f(T)$. In real conditions, tracks are maintained regularly. The simulation results processing allowed to establish the following mathematical model of the relationship

$$
P_{T P W}\left(t_{i}\right)=0.9975-2.3 \cdot 10^{-4} T .
$$

The correlation factor is $r=0.74$, the determination factor is $r^{2}=0.54$. The formula (21) can be applied in a range from 100 to 800 million tons gross.

To illustrate the application of the developed mathematical model for specific conditions, let's take a section of one of the railways of Ukraine. There are certain areas in the selected section where traffic load accumulated after TPW rehabilitation differs. We have used formula (21) to calculate probability for various values of the accumulated traffic load. The sections were ranked based on the calculated values. Let's assume that the probability of failure-free operation is $P_{T P W} \geq 0.95$, then all components of the TPW operate reliably in the selected site. If the probability of failure-free operation is $0.95>P_{T P W} \geq 0.85$, then one can assume that failure of defective individual components occurred and this is an indication that rehabilitation should be planned and scheduled. When $P_{T P W}<0.85$, the related areas should be included in rehabilitation plan as soon as possible. For a better visualization of above ranking there is a layout of a railway area provided below where each category of the failure-free operation is highlighted by a specific color (Fig. 1,a).

a)

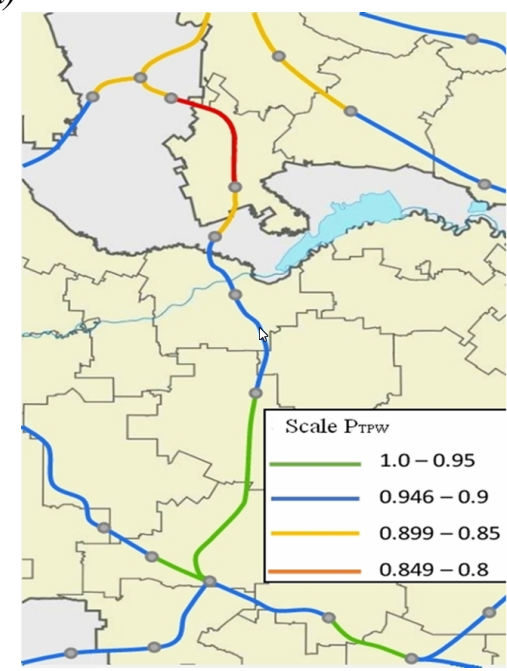

b)

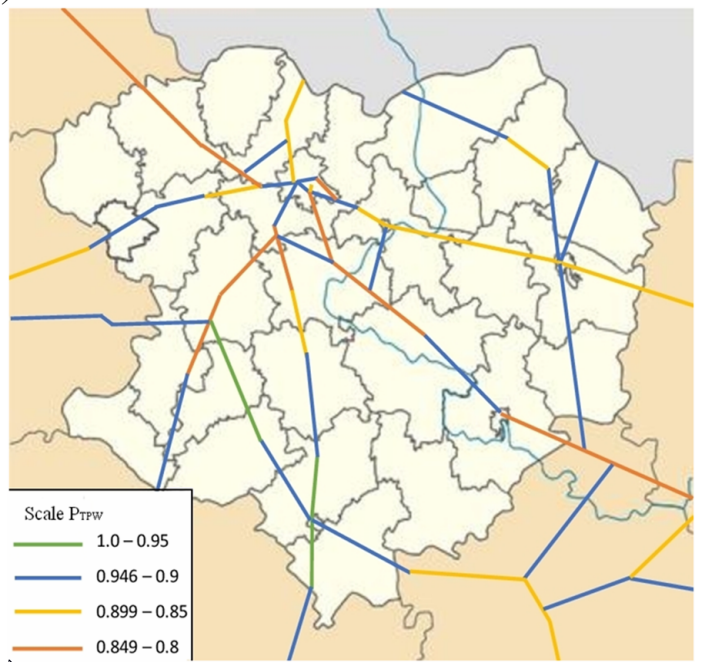

Fig.1. Classification of the railway track sections according to the probability of failure-free operation $P_{T P W}$

The management of this area is able to carry out long-term planning of the different types of repair and maintenance, taking into account the technical condition of the TPW. This allows to schedule maintenance, specify location, plan resources. A fairly simple software can calculate the probabilities daily, do classification and highlight the railway sections by color accordingly. Such daily monitoring will increase the operational reliability of this area and the entire railway in general (Fig. 1, b). 


\section{Conclusions}

This paper is the first step towards creating a risk management system in the railway industry. The developed mathematical model allows to determine probability of failure-free operation of all the components of the track permanent way: rails, sleepers, fastenings and ballast layer, which is new for the railway industry. The model allows ranking of the track sections by a degree of their "aging" and provides basis for timely planning of various types of tracks maintenance or repair.

In order to increase reliability of the track sections, the mathematical model can be used as a basis for technical condition monitoring of railways. This model considers the maximum possible number of factors that affects reliability of the transportation. Monitoring allows sorting track sections according to their fail risk degree and identify the most dangerous places that require additional inspection or repair. The model can be for rational planning and allocation of funding and resources.

\section{References}

1. L. Wang, Y. Li, E. Wang, Systems Engineering Procedia, 1, 174-180 (2011).

2. S. Lee, International Journal of Railway, 6 (2), 45-52 (2013).

3. J. H. Park, C. S. Shim, Journal of the Korean Society for Railway, 20 (3), 400-412 (2017).

4. J. M. Rocha, A. A. Henriques, R. Calçada, A. Rönnquist, Engineering Structures, 101, 138-149 (2015).

5. J. M. Rocha, A. A. Henriques, R. Calçada, Structure and Infrastructure Engineering, 12 (1), 78-92 (2016).

6. D. Lee, H. S. Lee, Journal of The Korean Society For Urban Railway, 5 (3), 867-871 (2017).

7. B. Leitner, Procedia Engineering, 187, 150-159 (2017).

8. B. Leitner, L.Môcová, M. Hromada, Procedia Engineering, 187, 143-149 (2017).

9. Z.Dvořák, E.Sventeková, D. ̌̌ehák, Z.Čekerevac, Procedia Engineering, 187, 548-555 (2017). doi: 10.1016/j.proeng.2017.04.413.

10. C.Jia, W.Xu, Y.Wang, Procedia Engineering, 15, 1293-1297(2011).

11. J. Sadeghi, H. Askarinejad, Structure and Infrastructure Engineering, 6 (6), 677-688 (2010).

12. S-H. Kim, Journal of the Korean Society for Railway, 14 (6), 569-574 (2011).

13. D.Ionescu, N.Brinzei, J-F. Petin, IFAC-PapersOnLine, 48 (21), 314-319 (2015).

14. K.Liu, M.Wang, W-H. Zhu, DEStech Transactions on Computer Science and Engineering, Jun 21; (mcsse), 421-425 (2017).

15. A.Shtompel, SWorld Journal, 13, 271-277 (2017). 